\title{
Beyond research skills training: an opportunity to support the wider 'ecosystem' of the part-time research student
}

Dr Carol Edwards

Study Adviser

Student Development Zone

David Wilson Library

University of Leicester

University Road

LEICESTER

LE1 7RH

ce46@le.ac.uk

01162522344

\begin{abstract}
This paper presents the findings from a UK study of one hundred part-time research students. The participants were students attending one of a series of training days provided specifically for part-time research students. Free text responses were collected on: what it's like being a part-time research student; what they would like from training events; and what they thought of this series of training days. The students were particularly appreciative of the opportunity to meet fellow part-time research students, albeit in different disciplines and at different stages of their PhD. Rather than solely listing specific research skills they would like covered, most of their ideas for future training sessions concerned more nebulous personal and emotional aspects of the experience of studying for a PhD on a part-time basis. Four dimensions of training need were identified: research techniques; research skills; engagement with the part-time PhD process; and engagement with their part-time peers. It is suggested that research training involving part-time research students, could usefully build in time to focus explicitly on some aspect(s) of the more personal and emotional elements of the part-time doctoral experience, as well as on technical aspects of research work.
\end{abstract}

Keywords: part-time, doctoral study, student experience, research training, research student, $\mathrm{PhD}$ 


\section{Introduction}

Part-time doctoral study is a popular route to take, particularly for mature students who have not come directly from a first degree (Kulej and Park 2008). However, despite constituting over a fifth of starters on PhD programmes in the UK (HEFCE 2009), and around one third of those starting PhDs in Australia (Cumming and Ryland 2004), little research has been undertaken on the experiences specifically of part-time PhD students. Evans $(2002,138)$ calls them 'the 'reserve army' of research students for universities'; and Neumann and Rodwell $(2009,55)$ suggest that part-time research students have been 'overlooked to the point that they are 'invisible', in both policy and research terms'.

National retrospective surveys of research student experience in both the UK (Kulej and Park 2008) and Australia (Graduate Careers Australia 2007) found reported levels of satisfaction among full-time and part-time research students were similar across most fields that were surveyed; for example regarding supervision, or thesis examination. But both surveys found part-time students to be less satisfied than full-time students with their ease of access to the 'intellectual climate' of their department and research institution.

Integration into one's departmental academic community is ideally not an optional extra, but an important component of doctoral level study. McAlpine, Jazvac-Martek and Hopwood $(2009,98)$ write about the 'day to day', 'taken-for-granted', 'informal' activities and conversations that contribute to doctoral students' 'feeling of being an academic or belonging to an academic community'. They report data from Canada and the UK showing that, in addition to the specific 'more structured and often benchmarked features of doctoral experience' (p. 107) a range of less formal activities is also important. Such activities tend to flow from physical proximity to other researchers, and part-time students inevitably have fewer of these opportunities. 
Vitae exists in the United Kingdom to support the 'personal, professional and career development of doctoral researchers and research staff in higher education institutions and research institutes' (Vitae 2010). Its national team is based in Cambridge, and it has eight regional hubs across the UK. The Midlands Hub is one of these.

In 2008, the Midlands Hub of Vitae organised a series of six training days specifically for part-time research students. This training would gather together a relatively large number of part-time research students, so the opportunity was taken to conduct some research alongside the standard evaluation process, to investigate more broadly how part-time research students feel about research training. The research proposal was reviewed and approved through the internal ethics review process of the University of Leicester. All 100 students attending one of the training days were invited to take part.

\section{Training days for part-time research students}

Six training days were held (Vitae, 2009); one at each of six different UK Midlands universities. Each day took the same overall format, but included a different choice of training topics in the afternoon. The days were free to attend for any part-time researcher from any Vitae Midlands Hub university. Two parallel workshops were offered in the afternoons. One was informally labelled in the planning process as 'nuts and bolts' topics, and included for example 'Structuring your thesis' and 'Academic writing styles'. The other was informally labelled 'motivation and management'; examples of which are 'Getting the best from long-distance supervision' and 'Making progress: avoiding defeatism and selfsabotage'.

\section{The Study}

The study was an extension of the routine feedback process, rather than being designed from the start as a separate research study, so there were limitations on the data collection opportunities available. Relatively little research has been published on what part-time 
research students need from research training, so it was decided not to use a questionnaire with pre-coded response options. Such an enquiry instrument could miss valuable insights, descriptions and examples that these participants may be able to give.

Working within the time and budgetary constraints of the project, the aim was to maximise the opportunity offered to participants to record, in their own words, how they felt about their part-time doctoral study and about their research training. It was therefore decided to:

- use a written rather than a verbal response format, so that simultaneous data collection was possible involving all participants, thus maximising the number of respondents and minimising the time taken

- maintain minimum influence over responses by using only open questions and inviting free-text responses

- encourage thoughtful and unhurried responses by allocating protected time during the training days for respondents to record their responses

- try to obtain a more immediate and authentic picture of the feelings of respondents by collecting data at three separate points over the course of each training day: before the first session began; straight after return from lunch; and after the last session

- make all responses completely confidential, with a total absence of identifying information, to encourage as free responses as possible.

This last decision about confidentiality meant that no demographic data can be associated with individual responses. This may feel like a lost opportunity. However, if the total number of respondents (100) is disaggregated by their wide range of backgrounds, disciplines, institutions, ages, and academic backgrounds, the very low numbers in each 'cell' would not support any statistical analysis, so no valid conclusions could in any case be made about subgroups. 


\section{The questions}

As students arrived for a training day they were give an A4 sheet with three questions, and space for free-text responses. The rationale for this point of enquiry was to collect data on their feelings as close to the workshop as possible, but without a chance for them to have adjusted their perceptions, hopes, and expectations, in response to what was provided. The aim was to gain insight into the personal context, as well as the intellectual context, into which the training was being delivered. The following box shows the questions asked at different points during the day.

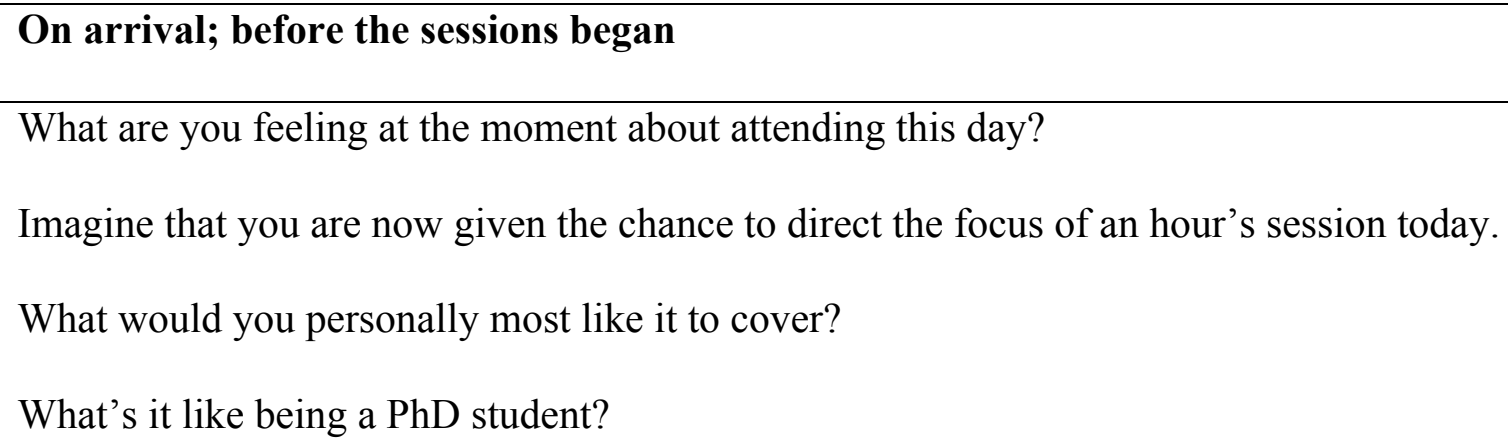




\section{Findings}

One hundred researchers registered to attend the workshops. Demographic data collected when students registered for the training days, and from observations during the training days, showed there was diversity of age, gender, stage of study, discipline, institution of study, and activities and commitments outside their study. Some participants were employed as academic researchers, and were doing their $\mathrm{PhD}$ alongside their daily work; some were in other full- or part-time employment; some were doing the $\mathrm{PhD}$ as a hobby. Response rates for the individual questions ranged between $74 \%$ and $92 \%$.

For each question in turn, all of the free-text responses were read, then sorted into broad collections of comments that seemed to express related ideas. The main themes were then identified from these broad collections, and are presented below.

\section{Question 1: What are you feeling at the moment about attending this day?}

Ninety two responses were collected. Responses could be assembled under the five main themes shown in Table 1. 
Table 1: Main themes within the responses to the question: What are you feeling at the moment about attending this day?

\begin{tabular}{|c|c|}
\hline Enthusiastic & Nervous \\
\hline 'Ready to learn' & 'Apprehensive. Desperate' \\
\hline 'Excitement and curiosity' & 'Slightly anxious; uncertain about what to \\
\hline 'Anticipating a fascinating day!' & expect' \\
\hline 'Open-minded' & 'Perhaps a little under-qualified' \\
\hline 'Hopeful and interested' & \\
\hline Looking forward to meeting others & Glad I've found the right place \\
\hline 'Looking forward to meeting other part-time & 'Glad to have found the right place' \\
\hline PhDs. Hope to learn from each other. May & 'Very pleased that part-time students have a \\
\hline help to put own problems/studies into focus' & chance to access training' \\
\hline 'I am feeling good about the opportunity to & 'It's great to have this opportunity' \\
\hline meet other researchers at this event' & 'Interested, grateful, looking forward to \\
\hline 'Excitement at meeting other students' & interaction with others' \\
\hline \multicolumn{2}{|l|}{ Hope it'll be worthwhile } \\
\hline \multicolumn{2}{|l|}{ 'Sceptical but interested' } \\
\hline \multicolumn{2}{|c|}{ 'A bit apprehensive. Don't know what to expect and hoping for answers' } \\
\hline \multicolumn{2}{|c|}{ 'Should I be here or should I use this day in Birmingham Central Library where I am working } \\
\hline \multicolumn{2}{|l|}{ on primary sources? Hope it's worth it!' } \\
\hline \multicolumn{2}{|c|}{ 'Curious. Apprehensive - will it be useful? Or will I be made to do a lot of exercises which } \\
\hline \multicolumn{2}{|l|}{ are of no relevance to my research/situation? } \\
\hline \multicolumn{2}{|c|}{ 'Tired and feeling overwhelmed with work. Perhaps I should be elsewhere making some } \\
\hline progress.' & \\
\hline
\end{tabular}


The overall feeling was of excited anticipation, tempered with slight apprehension. There was relief and a degree of gratitude that something like was being made available specifically for part-time research students, but there was also a level of concern over whether it would turn out to be the best use of their time. Some said that they were particularly looking forward to meeting other part-time researchers.

\section{Question 2: Imagine that you are now given the chance to direct the focus of an hour's} session today. What would you personally most like it to cover?

This question was included to gain insight into the mass of research training needs that such a group of students might present with. Eighty nine responses were collected, and four main themes were identified. Table 2 shows examples of quotes collected under each of these four main headings.

Table 2: Main themes within the responses to the question: Imagine that you are now given the chance to direct the focus of an hour's session today. What would you personally most like it to cover?

\begin{tabular}{|l|l|}
\hline Research techniques & Research skills \\
\hline 'Use of Endnote' & $\begin{array}{l}\text { 'The process of writing' } \\
\text { 'Structuring your thesis' } \\
\text { 'Covering of existing relevant research } \\
\text { techniques' }\end{array}$ \\
'Systematic literature reviewing' & 'To understand how best to write up qualitative \\
\hline Engaging with the doctoral process & research in a critical manner' \\
\hline 'How to stay motivated' & 'Troubleshooting i.e.: problems people have \\
is not something you're doing all the time & overcome them' \\
- only for a few hours.' & 'Whether I am alone or perhaps everyone else \\
\hline
\end{tabular}




\begin{tabular}{|l|l|}
\hline $\begin{array}{l}\text { 'Time organisation - stages that we should } \\
\text { go through - long term and short term }\end{array}$ & $\begin{array}{l}\text { is experiencing the same things??' } \\
\text { 'Discuss with other participants about there area } \\
\text { 'Getting pen to paper!' }\end{array}$ \\
'Confidence in one's ability' & $\begin{array}{l}\text { their research experience' } \\
\text { 'Tips and tricks of staying focused on the PhD }\end{array}$ \\
'As a distance part-timer, how to get the & route for part-time' \\
best out of what is available' & 'Sharing ideas about how to go about this task' \\
'Not getting overwhelmed' &
\end{tabular}

Sorting suggestions into these four main themes allows us to begin to tease apart the different types of training that these students were looking for.

\section{Question 3: What's it like being a PhD student?}

Eighty six responses were collected for this question. Some replies were solely negative e.g.: 'Lonely, anxious'; some were solely positive e.g.: 'Good. It's a privilege. It is a distraction in itself'. Another group of replies concerned the juggling of study with other priorities e.g.: 'Very hard being part-time, juggling work and children so that research is third priority'. The largest group of replies, however, was those that expressed both positive and negative feelings, often within a short sentence, for example: 'Mentally stimulating but disheartening'; 'Lonely, isolated, absorbing, satisfying (but at the same time confusing ...) and frustrating'. Table 3 shows the varied ways in which this co-existence of feelings was expressed.

Table 3: Main themes within the responses to the question: What's it like being a PhD student?

'Full of ups and downs.'

'Mentally stimulating but disheartening'.

'Lonely, isolated, absorbing, satisfying (but at the same time confusing ...) and frustrating.' 'Lonely, stressful, but ultimately rewarding.' 
'Interesting, challenging, fun, disconnected, constrained by system, sometimes lonely.' 'STIMULATING, CONFUSING, SCARY, EXCITING! Move from being able to 'hold' the lack of structure and 'not knowing' where next, to having to become focussed and specific. Remembering issues of in-depth focus on a Q, and research training components need to balance.'

'Stressful, frustrating and stimulating.'

'Hell! But very interesting.'

'Challenging, exciting, thought-provoking, motivating, stressful, anxiety-provoking, privileged.'

'Sometimes great. I'm very enthusiastic about my subject and it is such a privilege and feels so self-indulgent. Sometimes - more often - it is a great burden and I feel very guilty about spending time on this when there's so many other pressures on my time.'

Question 4: You've had the morning sessions, and you've had lunchtime to talk to people: how are you feeling about the day at this stage?

Eighty three responses were received. Of these, eight were negative, four were neutral, 50 were positive, and a further 21 responses focussed specifically on how great it was to be mixing with fellow part-time research students. Table 4 shows some representative responses. Table 4: Main themes within the responses to the question: You've had the morning sessions, and you've had lunchtime to talk to people: how are you feeling about the day at this stage?

\begin{tabular}{|l|l|}
\hline Negative responses & Positive responses \\
\hline 'I think it's been useful to talk with other & 'Positive. Energised.' \\
PhD students about their experiences. Some & 'Very positive. Enjoyable.' \\
of the sessions have confirmed that other & 'Great'. \\
students are experiencing similar issues, but I & 'Today has worked out far more useful than I \\
\hline
\end{tabular}




\begin{tabular}{|c|c|}
\hline don't feel that I've moved forward in terms & could have imagined, \\
\hline of developing strategies to deal with them.' & 'Enioving it', \\
\hline 'It has been extremely reassuring to discover & 'Stimulated / inspiring / positive.' \\
\hline that the difficulties I have been experiencing & 'Very good! Made some really useful \\
\hline as a part-time student are largely shared. & contacts. Some great insights.' \\
\hline However, I feel that the morning sessions & 'Comfortable - useful to reflect on \\
\hline $\begin{array}{l}\text { would have been more constructive if they } \\
\text { had focussed on particular areas, as opposed } \\
\text { to allowing discussion to drift.' }\end{array}$ & own/others' experiences.' \\
\hline \multicolumn{2}{|c|}{ The value of talking with other part-time doctoral students } \\
\hline 'Glad I came as it's been good to meet other & "Very useful to get away to talk to others \\
\hline part-timers - most of the colleagues I have & who are in the same boat. Interesting to find \\
\hline met on university-based courses have been & out about other research areas.' \\
\hline full-time.' & 'It was interesting to find out what the people \\
\hline 'Am taking advantage of various & at the various stages were experiencing.' \\
\hline conversations - it has been worth attending.' & 'Energised by meeting people in a similar \\
\hline 'Good to hear people have similar problems & situation and discovering problems. Also \\
\hline and issues - so not feeling like the only one. & thinking through issues relating to the \\
\hline Also to hear other perspectives and & process of doing a PhD.' \\
\hline experiences. Interesting to hear different & \\
\hline university criteria.' & \\
\hline
\end{tabular}


The two negative responses in Table 4 hint that some sessions were not as successful as they could have been. These sessions were those that encouraged a significant level of input and direction by the research students themselves. Such sessions can be useful in allowing students to de-brief and to share difficulties and ideas. However, they also need careful and skilled facilitation to build constructively on the material that is brought, and make it relevant and useful across the whole group, There is a fine line between facilitating such sessions to be empowering, relevant, and creatively constructive; or letting them slide towards a general chat about shared difficulties.

\section{Question 5: Thinking about your conversations over lunchtime, what PhD-related} elements did you find people wanted to talk about most?

Eighty two responses were received. The most commonly recorded topics were: time management/work life balance; supervision; overcoming difficulties encountered; and the nature and process of $\mathrm{PhD}$ experience. These are fairly generic $\mathrm{PhD}$ topics rather than discipline-specific subjects, and enabled the students to de-brief and swap stories across discipline boundaries.

\section{Question 6: If you were given unlimited resources to run a half-day PhD (part-time)-} related workshop, what would you be tempted to include?

This gave the students another chance, half-way through the training day, to say what they would really like to have a workshop on, given unlimited resources. Among the 74 responses, there was a scattering of specific suggestions e.g.: 'How to edit your work'; but the great majority of respondents wanted more underlying, unspecific, general support for this parttime $\mathrm{PhD}$ process. Table 5 gives examples of the range and extent of these broader ideas for workshops. 
Table 5: Typical examples of responses to the question: If you were given unlimited resources to run a half-day $\mathrm{PhD}$ (part-time)-related workshop, what would you be tempted to include?

'Time to communicate 'sob stories'.'

'How not to get a $\mathrm{PhD} . '$

'Top tips. Write-up. Advice and pitfalls. Advice re viva.'

'Achieving a balance. Milestones. Show-stopping knowledge (must knows).'

'Maybe a handout with some of the world's best tips for managing part-time students, plus quotes and truisms ...'

'It would be helpful to have discussions re pastoral care in the PhD context - wide definition.'

'Emotional intelligence.'

'Time management. Structure and essence of a $\mathrm{PhD}$. Resources. What is a $\mathrm{PhD}$ ? Networking and swapping stories and contact details with other part-time students.'

'I would not know where to start to answer this: there's a case for going with the flow, as the group dictates.'

'Making progress; way to go; where we find information; people who experience part-time PhDs.'

'How to stay happy and motivated! Reaching out for peer support. How to avoid isolation.' 'Talks from those who have completed a PhD part-time. Transferable skills identification.' 'Debate about the meaning of $\mathrm{PhD}$. Good points / bad points.

'Give people time to talk to each other about their work and problems they are encountering. Somebody could give a presentation, followed by a discussion with the group. Each person would do this in turn.'

'Short skills-based sessions e.g.: keeping track of your reading, writing journal articles and 
getting published.'

'Lots of time to discuss issues with other participants in structured way. How to work within part-time constraints. Thinking through the process of doing a PhD etc.'

\section{Question 7: What did you get out of being a participant at this event?}

\section{Question 8: What did you enjoy most about the part-time researcher event?}

The responses to these questions were considered together as they produced fairly similar responses. Some respondents identified their favourite session; but most wrote about more general issues such as the enjoyment they had got from meeting and working with fellow part-time research students; and the increased motivation that they were going away with.

Table 6: The two main themes among responses at the end of the training days

\begin{tabular}{|l|l|}
\hline Engaging with the doctoral process & Engaging with peers \\
\hline 'More confidence that I am doing OK.' & 'People! There's life beyond my bubble (the \\
less isolated. More ideas began to flow. I felt & helped organise my thoughts loads - \\
encouraged.' & thanks!).' \\
'Reassurance, tips, nuggets of information, & 'Feeling part of a community. Excellent food \\
support.' & and good organisation - made to feel \\
'Lots. I was stuck and now feel motivated.' & welcome.' \\
'A kick to get on with it.' & 'Interacting with other part-time PhD \\
'Encouragement to continue, and re- & students - even just chatting/socialising.' \\
energised.' & 'Being able to discuss with other students \\
'The opportunity to take time out and focus & across the board common problems and also \\
on what it means to be a successful & 'Informal interaction with other part-time \\
\hline
\end{tabular}


\begin{tabular}{|l|l|}
\hline & 'ime researchers.' \\
\hline
\end{tabular}

These two categories match two of those identified in the earlier responses about what the students wanted from a research training session.

\section{Discussion}

This study was opportunistic in building upon a routine evaluation process; and the sample was one of convenience, in that all one hundred of the part-time research students attending any one of the six training days were invited to take part. The research design and scope were therefore severely limited by time and budgetary constraints. Working within these limitations, the data collection process was designed to facilitate the recording of thoughtful, authentic, free-text comments by respondents. A large collection of comments was gathered, offering insight into what this sector of students wants from research training.

The students were self-selecting in that they had decided to take time to attend a study day, so it is possible that they are not representative of the wider community of part-time doctoral researchers who did not attend. The potential effect of this possible bias is, however, unclear. Students choosing not to attend may have done so for positive reasons e.g.: feeling confident at the moment; but also for negative reasons e.g.: too pushed for time to take a 'day out'. The findings can not be taken as statistically generalisable. The emphasis instead is on their potential transferability (Guba and Lincoln 2001): they are offered to readers to consider for themselves their potential relevance and usefulness within their own doctoral supervision and research training and support practice.

\section{Stepping back from the technical}

Key academic elements that distinguish doctoral level, from undergraduate and master's level study, are the depth of investigation, and the level of critical analysis. But these academic challenges were almost invisible among those voiced by these part-time students. Instead, respondents used predominantly informal rather than technical descriptors of their hopes for 
the training day, and what they felt they had gained from it. These descriptors located their doctoral study firmly within their personal lives as much as within academia.

Hinsliff-Smith et. al. $(2009,1)$ criticise past studies for having 'viewed the academic and social dimensions of doing a $\mathrm{PhD}$ as serving quite different purposes'. They suggest that 'academic support can and does take place in a social setting, and vice versa.' Cumming $(2010,32)$ writes about 'identifying intersections and overlaps' in doctoral work, and aiming 'to blur rather than demarcate boundaries, and to establish emerging patterns and relationships'. The responses recorded in this study were derived within what were very mixed groups of participants regarding age, gender, stage of $\mathrm{PhD}$, institution, and research discipline. Sharing of experiences and ideas across these boundaries was still highly valued. This link across academic and personal; and technical and emotional; was clearly evident in the study data, and will guide discussion of the study's findings.

\section{Beyond research skills training}

These findings provide evidence that research skills training sessions can be a useful forum for aiming to go beyond pure research skills training. Deem and Brehony $(2000,156)$ suggest that 'Research training cultures sit on the boundaries between research student cultures and discipline-specific cultures'. Hinsliff-Smith et. al. $(2009,10)$ recognise the potential this offers, and suggest that 'The special role of research methods training in enhancing peer support needs further exploration'.

The present study found strong evidence to support these propositions. This suggests that it may be useful to be proactive, in planning to use research training sessions as opportunities to support a broader discussion of how research culture and practice fit within the wider lives of part-time research students. This fits with Cumming's $(2010,25)$ proposal for 'a broader and more holistic conception of doctoral education'. 
The induction, and other such prosaic processes, may also offer this potential. McCulloch and Stokes $(2004,1)$ suggest that:

'It is very easy for a part-time student to minimise their engagement with induction.

To do this is a mistake. Induction is the beginning of the research student's socialisation into the academic culture, the doctorate is designed to make them part of.'

This preference for avoiding anything but apparently specifically relevant training was also noted by Collinson and Hockey (1997), and was hinted at by some of our study participants, who arrived expressing the hope that the day would be worthwhile, as there were plenty of other calls on their time. This narrow view of what may be strictly useful, and therefore whether time can be spared to attend, is one that needs to be acknowledged when planning and advertising training provision. Otherwise part-time research students could miss out on the added value, not so easily quantified or packaged, that lies beyond pure technical skills training or information provision, and which relates more to ways of engaging with the $\mathrm{PhD}$ process and with one's peers.

\section{Holding widely differing feelings at the same time}

This study found that it was common for part-time research students to hold seemingly widely different positive and negative feelings about their study at the same time. They could be hugely enthused but also very despondent; very excited but also highly frustrated; feeling privileged but also resentful. The existence of these extreme and opposing feelings, in addition to the challenge of their academic work and of their other work and family commitments, presents a potential threat to their level of emotional wellbeing. McAlpine, Jazvac-Martek and Hopwood $(2009,108)$ were 'intrigued by the balancing represented ... between the positive experiences of feeling like an academic/belonging to an academic community and the challenging experiences of lack of time and negative affect.' 
Their participants were 23 full-time students, 20 of whom were studying in Canada under a more formal taught schedule than is found in the UK; most of whom were looking ahead to an academic career. The authors ask (p. 108) 'to what extent do we make explicit what is a central experience of the doctorate and future academic work - the variation in affect from the pleasures of being acknowledged as an academic to the anxieties and frustrations of living with and reconciling multiple demands?' They suggest that issues of affect need to be raised explicitly, to dissipate potentially undermining feelings of inadequacy.

Full-time research students can at least usually observe other researchers; and can de-brief with fellow research students, or with post-doctoral researchers. Part-time research students are much less likely to have such ready access to observation of other researchers, and to peer interaction and support. Working in more isolation, and often with other major areas of their life competing for attention, the existence of such extremes and switches of emotion may be particularly disconcerting and tiring. These feelings of being torn, not only by competing demands, but also by wildly differing emotions, could usefully be acknowledged explicitly and early on, by supervisors, and by those involved in providing induction and research training for part-time research students. This could be an important step in supporting students in achieving an acceptable, workable, and productive balance.

\section{Four dimensions of the research training needs of the part-time researcher}

Cumming $(2010,25)$ writes about 'the doctoral interface - the points at which education, training, research, work and career development intersect.' He proposes (Cumming 2010, 36) 'the concept of an 'ecosystem' of many components that are interdependent as well as interrelated.' The current study has been inquiring at that doctoral interface, and the notion of an ecosystem is useful in the interpretation of the findings. It also links with the environmental metaphor of 'intellectual climate'. 
Access to 'intellectual climate' is one of the six key dimensions investigated in research student experiences surveys (GCA 2007; Kulej and Park 2008), and is the one where parttime research students consistently report particularly low levels of satisfaction compared with those of their full-time peers.

The particular relevance and importance of their part-time status was described succinctly by one respondent, who wrote:

'The experience $<$ of training $>$ would be better if an acknowledgement of the particular difficulties faced by part-time students was more explicit. Part-time students often feel that they have to fit into an inflexible mode of working and such perspectives can hamper progress e.g.: anxieties about lack of productivity at the early stages in the literature review and planning.'

The student is explaining that part-time doctoral study is not simply a longer version of fulltime doctoral study, but a qualitatively different experience in many ways, and that any training days specifically for this group of students could usefully attend to the differences. Four distinct, although interrelated, elements have been identified in this study, which could form the foundation of the working ecosystem of the part-time research student. They are: research techniques, research skills, engaging with the doctoral process, and engaging with peers (Table 2). The elements of research techniques and research skills can operate at an intellectual level, but engagement with the doctoral process and with other part-time research students involves the researcher at a more personal and human level.

\section{Conclusion}

This study has investigated the feelings of part-time research students about their training needs. A strong finding is the great importance that part-time research students place on the opportunity to meet up with fellow part-time research students. Another strong finding is that life as a part-time researcher can be like living on a seemingly uncontrollable see-saw, where 
the requirements of the $\mathrm{PhD}$ lie at one end; their other life and work commitments lie at the other; and the student is swinging between them but never achieving a balance.

While part-time research students share many concerns with their full-time counterparts regarding the technicalities of studying for a $\mathrm{PhD}$, they feel that being a part-time research student is a very different experience overall, and that this needs to be acknowledged throughout the training and support they are offered. The actual task of achieving a $\mathrm{PhD}$ may be similar for part-time and full-time research students, but the context in which the task is being performed can be very different. This may be why respondents emphasised their need for training that covers a much broader remit than solely research techniques and skills. The students' suggestions for training fell into four distinct areas: research techniques; research skills; engaging with the doctoral process; and engaging with peers. These four areas could be thought as the four foundations of the ecosystem of the part-time doctoral researcher. When planning research training, it could be useful to bear all four foundations in mind, so that broader coverage can be built into training wherever possible. This awareness can also inform the supervision process.

A challenge for the facilitator, when going beyond purely academic skills training, and into peer-led interaction and de-briefing, is how to keep hold of the wider relevance, so that all participants can benefit. De-briefing can be extremely useful to those individuals who manage to negotiate space in a session to describe their own situation, but the facilitator needs to ensure that the topics discussed are further developed within that session, to be made relevant and useful for all members of the group.

\section{Acknowledgements}

The data collection and initial analysis were funded by Vitae. Further analysis and the preparation of the article were funded by the University of Leicester. I would like to acknowledge the support and encouragement of the project team, namely, Tristram Hooley, 
Kate Mahoney, Ged Hall, and Heather Dalgleish; and of my colleagues Maria Graal and Steve Rooney in Student Development at the University of Leicester.

\section{References}

Collinson, J. and Hockey, J. (1997) The social science training model doctorate: student choice? Journal of Further and Higher Education 21 373-381

Cumming, J. (2010) Doctoral enterprise: a holistic conception of evolving practices and arrangements. Studies in Higher Education 35 25-39

Cumming, J. and Ryland, K. (2004) Working doctoral students: challenges and opportunities. AARE National Conference, December 2004. Available at: http://www.aare.edu.au/04pap/cum04508.pdf Accessed 28 ${ }^{\text {th }}$ September 2010

Deem, R. and Brehony, K. (2000) Doctoral students' access to research cultures - are some more unequal than others? Studies in Higher Education 25 149-165

Evans, T. (2002) Part-time research students: the 'reserve army' of research students for universities. In Quality in postgraduate research: integrating perspectives, Eds. M. Kiley, and G. Mullins, 138-144. Canberra: University of Canberra Graduate Careers Australia. (2007) Postgraduate research experience 2006. The report of the Postgraduate Research Experience Questionnaire. Carlton, Victoria: Graduate Careers Australia. Available at: http://www.graduatecareers.com.au/content/search Accessed $28^{\text {th }}$ September 2010

Guba, E. G. and Lincoln, Y. S. (2001) Guidelines and checklist for constructivist (a.k.a. fourth generation) evaluation. Available at: http://www.wmich.edu/evalctr/archive_checklists/constructivisteval.pdf Accessed $28^{\text {th }}$ September 2010 
HEFC. (2009) PhD study: trends and profiles 1996-1997 to 2004-2005. Higher Education Funding Council for England. Available:

http://www.hefce.ac.uk/pubs/hefce/2009/09_04/\#exec Accessed 28 $8^{\text {th }}$ September 2010 Hinsliff-Smith, L., Keane, J., Whiteoak, D. and Hawker, I. (2009) How to win friends and influence people: the value of the cohort in a doctoral research training programme.

Nottingham: Nottingham Jubilee Press. Available at:

http://www.nottingham.ac.uk/education/documents/research/jubileepress/jp2009hinsliffsmithetal.pdf Accessed $28^{\text {th }}$ September 2010

Kulej, M., and Park, C. (2008) Postgraduate research experience survey. Final report 2008. York: The Higher Education Academy.

McAlpine, L., Jazvac-Martek, M. and Hopwood, N. (2009) Doctoral student experience in education: activities and difficulties influencing identity development. International Journal for Researcher Development 1 97-112

McCulloch, A. and Stokes, P. (2004) The part time student. Published on Graduate Junction at: http://www.graduatejunction.net/site/part time_article Accessed $28^{\text {th }}$ September 2010 Neumann, R. and Rodwell, J. (2009) The 'invisible' part-time research students: a case study of satisfaction and completion. Studies in Higher Education 34 55-68

Vitae. (2009) Understanding the part-time researcher experience. Cambridge: Careers Research and Advisory Centre. Available at: http://www.vitae.ac.uk/CMS/files/upload/Parttime\%20researcher\%20experience.pdf Accessed $28^{\text {th }}$ September 2010

Vitae. (2010) Available at: http://www.vitae.ac.uk/ Accessed $28^{\text {th }}$ September 2010 